\title{
Cribriform Adenocarcinoma Salivary Gland-Type of the Nasopharynx: Case Report and Review of the Literature
}

\author{
Touria Bouhafa, Abderahman Elmazghi, Ouafae Masbah, Khalid Hassouni \\ Departement of Radiotherapy, CHU HASSAN II Fez, Faculty of Medicine and Pharmacy, Fez, Morocco \\ Email: cancer05ino@yahoo.fr, elmazghi@homail.com, masbahouafae1979@yahoo.fr, hassouni@hotmail.com
}

Received 20 January 2014; revised 18 February 2014; accepted 26 February 2014

Copyright (C) 2014 by authors and Scientific Research Publishing Inc.

This work is licensed under the Creative Commons Attribution International License (CC BY).

http://creativecommons.org/licenses/by/4.0/

cc) (i) Open Access

\begin{abstract}
Primary salivary gland-type carcinoma of the nasopharynx is a rare malignancy with aggressive clinical behavior and poor prognosis. Few cases have been reported in the literature. We report the case of a salivary gland-type carcinoma of the nasopharynx diagnosed in a 70-year-old woman managed in department of radiotherapy at Hassan II University Hospital in Morocco. The patient received a total of $70 \mathrm{~Gy}$ of radiations, which were divided into 2 Gy per session during 7 weeks. Follow-up was performed regularly, including nasal endoscopic examination and nasopharyngeal CT. Evolution was marked by disease control after 12 months of follow-up. The aim of this work is to show the rarity of this entity, describe clinical, radiological and histological features and finally discuss the treatment management.
\end{abstract}

\section{Keywords}

Nasopharynx, Cribriform Adenocarcinoma Salivary Gland-Type, Radiotherapy

\section{Introduction}

Adenoid cystic carcinoma (ACC) is the most common histological subtype of salivary gland malignancies, but it is very rare in the nasopharynx, with relatively few cases reported in the literature. Some of these cases are poorly documented and not well characterized given to the rarity of cases. The ACC is characterized by a slow evolution but locally aggressive and high risk of recurrence. The optimal treatment remains debated, even though recent evidence provides support for a multimodality approach [1] [2].

\section{Case Presentation}

We report a case of a 70-year-old woman, diagnosed and treated in radiotherapy department at Hassan II Uni-

How to cite this paper: Bouhafa, T., Elmazghi, A., Masbah, O. and Hassouni, K. (2014) Cribriform Adenocarcinoma Salivary Gland-Type of the Nasopharynx: Case Report and Review of the Literature. Open Journal of Pathology, 4, 79-82.

http://dx.doi.org/10.4236/ojpathology.2014.42012 
versity Hospital in Morocco. The patient had in her medical history a cardiac failure, but no prior smoking or radiation. She presented 6 months before the diagnosis, unilateral hearing loss with nasal obstruction. Clinical examination found a 3-centimeter lymph node of the IVth left cervical area. Nasopharyngeal endoscopy had showed a tumor process occupying totally the nasopharynx. Chest x-ray and blood tests were normal. A contrast computed tomography (CT) of the facial cranium and neck had showed an extensive lesion occupying all the nasopharynx with absence of bony erosion or involvement of adjacent structures. It revealed also two cervical ganglions with central necrosis in the jugulo-carotid area. The patient underwent a biopsy of the nasopharyngeal mass, under general anaesthesia. Histology revealed a cribriform adenocarcinoma salivary gland-type (Figure 1).

Regarding treatment strategy, Patient received radiotherapy alone without chemotherapy given to the geriatric assessment and co-morbidities. She received a total of $70 \mathrm{~Gy}$ of the radiations, divided into 2 Gy per session over a period of 7 weeks. Follow-up with nasal endoscopic examination and nasopharyngeal CT was performed and showed no recurrence 12 months after the end of treatment.

\section{Discussion}

Primary salivary gland type carcinoma is one of the most common malignancies of salivary gland origin, with widely varied histological subtypes, diverse clinical behaviours, and different prognoses [1]. Previously termed "cylindroma" by Bilroth in 1856, the adenoid cystic carcinoma (ACC) is the most common histologic subtype of the salivary gland malignancies, but it is very rare in the nasopharynx. A few cases had been reported in the literature. It is the most common malignancy of the submandibular and minor salivary glands and it can be seen in other glandular tissues such as the lacrimal glands, ceruminous glands of the external auditory canal, esophagus, breast, prostate, uteri cervix and Bartholin's glands [3] [4]. In the nasopharynx, the primary salivary gland type carcinoma is an uncommon malignancy that represents about $0.48 \%$ of all nasopharyngeal cancers [5], likely owing to the low density of salivary gland tissue in the nasopharynx. Within the nasopharynx, adenoid cystic carcinoma is the most common salivary gland tumor, followed by adenocarcinoma [5]. This tumor is considered to be derived from nasopharyngeal surface epithelium rather than from underlying minor salivary glands, based on histological appearance and immunohistochemical staining profile [6]. ACC affects women predominantly and usually occurs in the $5^{\text {th }}$ and $6^{\text {th }}$ decade of life and is rare in people younger than age 20 [5]-[7]. Regarding histology, it presents three patterns, cribriform, tubular and solid. The cribriform (landular) pattern is the most classic and best recognized appearance, characterized by islands of basaloid epithelial cells that contain multiple cylindric, cyst-like spaces resembling swiss cheese. These spaces often contain a mildly basophilic mucoid material, a hyalinized eosinophilic product, or a combined mucoid hyalinized appearance. Sometimes, the hyaline-

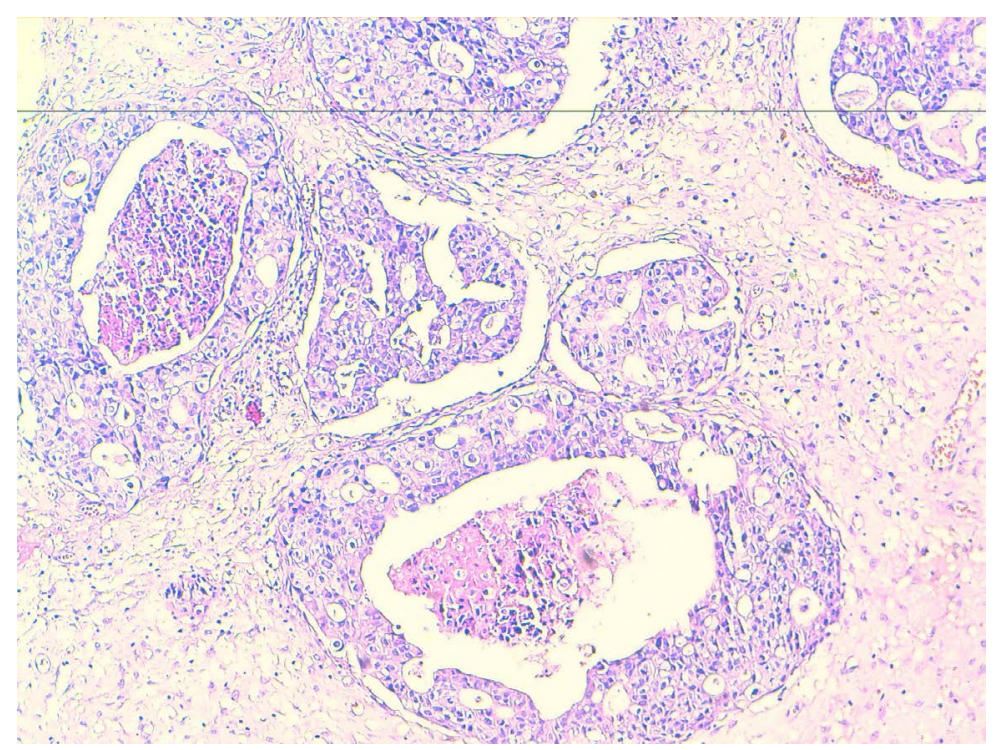

Figure 1. HES $\times 400$ definitive histologic examination indicating a cribriform adenocarcinoma salivary gland-type. 
ized material also surrounds these cribriform islands, or small strands of tumor are found embedded within this hyalinized stroma. The tumor cells are small and cuboidal exhibiting deeply basophilic nuclei and little cytoplasm. These cells are fairly uniform in appearance, and mitotic activity is rarely seen [8]. Mitotic figures are generally scarce in cribriform and tubular areas; however they are easily visualized in solid standards that have been associated with the worst prognosis [9]. The histological type found in our patient was the cribriform type, which is a subtype with better prognosis.

Adenoid cystic carcinoma of the nasopharynx has tendency to invade the nerves and to propagate perineurally ( $80 \%$ of the specimens found invaded). Even if some studies showed that there is not strong correlation between survival and perineural invasion alone, the majority believes that the invasion of a main nerve trunk or at least a large nerve by the tumor means a poor prognosis [6] [10] [11]. ACC typically presents an indolent and slow growth associated to frequent late distant metastases, which are together with local recurrences, the reasons for the low long-term survival rate [2]-[4] [12], in 70\% of cases metastases are localized at lung, it can also be done to the liver, bone [11] [13].

Multiple treatment modalities exist for the treatment of salivary gland tumors of the nasopharynx [14]. The best treatment for ACC, contains radical surgical resection followed by radiotherapy [7] [15]-[21]. In cases of nasopharyngeal ACC, the frequent perineural and perivascular infiltrations, associated with the anatomical characteristics of the nasopharynx, however, make the surgical approach risky on account of technical difficulties, due substantially to the proximity of surgical margins to critical neural and vascular structures [22]. The traditional therapeutic approach for patients with high-grade or unresectable (T4) disease is radiotherapy. A surgical approach is more appropriate for low-grade, low-stage adenocarcinomas [6].

Given the proven radiosensitivity of the ACC, this tumour is, in fact, regarded as a radiosensitive, even if not radiocurable, neoplasm, thus exclusive radiotherapy can determine a reduction in tumour volume with a meaningful improvement in the clinical symptoms [23] [24]. Vikram et al. reported regression of the tumoural mass in $96 \%$ of 49 patients treated only with radiotherapy, although in 93\% of the cases they observed recurrence of the disease within 5 years [22]. Although the surgical approach with attempts of oncological radicality, followed by radiotherapy, remains the treatment of choice for ACC, but exclusive radiotherapy is a good option in case of impossibility of surgery for general reasons or for technical difficulties. It is a valid therapeutic alternative guaranteeing good control of the disease and minimal side-effects. Moreover in the literature, many studies have shown that survival rates, over a long period of time, in patients with nasopharyngeal ACC do not seem to be significantly influenced by different (more or less aggressive) types of treatment [1] [22] [23].

In our patient, given to the impossibility of total resection, because of the locoregional extension, furthermore its geriatric assessment and co-morbidities, an exclusive radiotherapy was indicated. The evolution was marked by disease control at the imaging and endoscopy.

\section{Conclusion}

Nasopharyngeal cribriform adenocarcinoma salivary gland-type is an uncommon tumor with only very few cases reported in the literature. The treatment management must be discussed in a multidisciplinary approach for each case. Radiotherapy alone seems to be a good option in case of localized disease especially when chemotherapy is not applicable. But data are still insufficient for an appropriate treatment protocol or an accurate prognosis prediction for the disease and we still need larger clinical series and longer follow-up periods to establish the best treatment strategy for these patients.

\section{Conflict of Interests}

The authors declare any conflict of interests.

\section{References}

[1] Liu, T.-R., Chen, F.-J., et al. (2010) Primary Salivary Gland Type Carcinoma of the Nasopharynx: Therapeutic Outcomes and Prognostic Factors. Head \& Neck, 32, 435-444.

[2] Perzin, K.H., Gullane, P., Clairmont, A.C. (1978) Adenoid Cystic Carcinomas Arising in Salivary Glands: A Correlation of Histologic Features and Clinical Course. Cancer, 42, 265-282.

http://dx.doi.org/10.1002/1097-0142(197807)42:1<265::AID-CNCR2820420141>3.0.CO;2-Z 
[3] Papadas, T., Chorianopoulos, D. and Mastronikolis, N. (2007) Nasopharyngeal Adenoid Cystic Carcinoma: A Rare Nasopharyngeal Tumor. European Review for Medical and Pharmacological Sciences, 11, 55-57

[4] He, J.H., Zong, Y.S., Luo, R.Z., Liang, X.M., Wu, Q.L. and Liang, Y.J. (2003) Clinicopathological Characteristics of Primary Nasopharyngeal Adenocarcinoma. Chinese Journal of Cancer, 22, 753-757.

[5] Edge, S.B., Byrd, D.R., Compton, C.C., Fritz, A.G., Greene, F.L. and Trotti III., A. (2010) Pharynx: In AJCC Cancer Staging Manual. 7th Edition, Springer, New York, 41-56.

[6] Glicksman, J.T., et al. (2013) An Endonasal Approach to the Resection of a Papillary Seromucinous Adenocarcinoma of the Eustacian Tube. Journal of Otolaryngology—Head and Neck Surgery, 42, 12.

[7] Saadi, I., El Marfany, M., Hadadi, K., Amaoui, B., Kebdani, T., Errihani, H., et al. (2003) Adenoid Cystic Carcinoma of the Nasopharynx: A Case Report. Cancer Radiothérapie, 7, 190-194.

[8] Neville, B.W., Damm, D.D., Allen, C.M. and Bouquot, J.F. (2002) Oral \& Maxillofacial Pathology. W.B. Saunders Co., Philadelphia, 389-496.

[9] Carrasco, O.D. and Aldape B.B. (2006) Adenoid Cystic Carcinoma of the Dorsum of the Tongue: Presentation of a Case. Medicina Oral, Patología Oral y Cirugía Bucal, 11, E417-E420.

[10] Spiro, R.H., Huvos, A.G. and Strong, E.W. (1979) Adenoid Cystic Carcinoma: Factors Influencing Survival. American Journal of Surgery, 138, 579-583. http://dx.doi.org/10.1016/0002-9610(79)90423-9

[11] Spiro, R.H. (1997) Distant Metastasis in Adenoid Cystic Carcinoma of Salivary Origin. American Journal of Surgery, 175, 495-498.

[12] Nuti, C., Durand, M., Duthel, R., Seguin, P., Prades, J.M., Mosnier, J.F., et al. (1997) Les carcinomes adénoïdes kystiques du sinus maxillaire à développement intracrânien: Revue de la littérature, à propos d'un cas. Neurochirurgie, 43, 314-318.

[13] Gormley, B.W., Sekhar, L.N., Wright, D.C., Olding, M., Janecka, I.P. and Richardson, R. (1996) Management and Long-Term Outcome of Adenoid Cystic Carcinoma with Intracranial Extension: A Neurosurgical Perspective. Neurosurgery, 38, 1105-1112

[14] Liu, T.R., Chen, F.J., Zhang, G.P. and Yang, A.K. (2011) Different Therapeutic Strategies in Primary Salivary GlandType Nasopharyngeal Carcinomas. Current Opinion in Otolaryngology \& Head and Neck Surgery, 19, 87-91. http://dx.doi.org/10.1097/MOO.0b013e3283448402

[15] Lee, D.J., Smith, R.R., Spaziani, J.T., Rostock, R., Holliday, M. and Moses, H. (1985) Adenoid Cystic Carcinoma of the Nasopharynx. Case Reports and Literature Review. Annals of Otology, Rhinology, and Laryngology, 94, $269-272$.

[16] Jones, A.S., Hamilton, J.W., Rowley, H., et al. (1997) Adenoid Cystic Carcinoma of the Head and Neck. Clinical Otolaryngology \& Allied Sciences, 22, 434-443. http://dx.doi.org/10.1046/j.1365-2273.1997.00041.x

[17] Shotton, J.C., Schmid, S. and Fisch, U. (1991) The Infratemporal Fossa Approach for Adenoid Cystic Carcinoma of the Skull Base and Nasopharynx. Otolaryngologic Clinics of North America, 24, 1445-1464.

[18] Wang, C.C., See, L.C., Hong, J.H. and Tang, S.G. (1996) Nasopharyngeal Adenoid Cystic Carcinoma: Five New Cases and a Literature Review. Journal of Otolaryngology, 25, 399-403.

[19] Pitman, K.T., Prokopakis, E.P., Aydogan, B., Segas, J., Carrau, R.L., Snyderman, C.H., et al. (1999) The Role of Skull Base Surgery for the Treatment of Adenoid Cystic Carcinoma of the Sinonasal Tract. Head \& Neck, 21,402-407. http://dx.doi.org/10.1002/(SICI)1097-0347(199908)21:5<402::AID-HED4>3.0.CO;2-Z

[20] Schramm Jr., V.L. and Imola, M.J. (2001) Management of Nasopharyngeal Salivary Gland Malignancy. Laryngoscope, 111, 1533-1544. http://dx.doi.org/10.1097/00005537-200109000-00009

[21] Sur, R.K., Donde, B., Levin, V., Pacella, J., Kotzen, J., Cooper, K., et al. (1997) Adenoid Cystic Carcinoma of the Salivary Glands: A Review of 10 Years. Laryngoscope, 107, 1276-1280. http://dx.doi.org/10.1097/00005537-199709000-00022

[22] Vikram, B., Strong, E.W., Shah, J.P. and Spiro, R.H. (1984) Radiation Therapy in Adenoid-Cystic Carcinoma. International Journal of Radiation Oncology, Biology, Physics, 10, 221-223. http://dx.doi.org/10.1016/0360-3016(84)90007-5

[23] Alleyne, C.H., Bakay, R.A., Costigan, D., Thomas, B. and Joseph, G.J. (1996) Intracranial Adenoid Cystic Carcinoma: Case Report and Review of the Literature. Surgical Neurology, 45, 265-270. http://dx.doi.org/10.1016/0090-3019(95)00235-9

[24] Cao, C.N., Luo, J.W., Xu, G.Z., Gao, L., Xu, Z.G. and Tang, P.Z. (2013) Management of Nasopharyngeal Adenoid Cystic Carcinoma. Journal of Oral and Maxillofacial Surgery, 71, e203-e209. 